\title{
Copper Cu 64-DOTA-Trastuzumab
}

National Cancer Institute

\section{Source}

National Cancer Institute. Copper Cu 64-DOTA-Trastuzumab. NCI Thesaurus. Code C90576.

A radioimmunoconjug ate containing the recombinant humanized monoclonal antibody trastuzumab conjug ated with the bifunctional, macrocyclic chelating agent tetraazacyclododecanetetra-acetic acid (DOTA) and labeled with the radioisotope copper Cu 64 with radioisotopic activity and potential use as an imaging agent. The trastuzumab moiety of copper Cu 64-DOT A-trastuzumab binds with high affinity to the extracellular domain of human epidermal growth factor receptor 2 (HER2). Upon binding, the radioisotope moiety may be detected using positron emission tomog raphy (PET), thereby allowing the imaging and quantification of HER2-expressing tumor cells. HER2, a tyrosine kinase and client protein of heat shock protein 90 (Hsp90), may be overexpressed on the cell surfaces of various tumor cell types. 